Geraldo Nagib Zahran Filho

\title{
A Tradição Liberal dos Estados Unidos e sua Influência nas Reflexões sobre Política Externa
} Um Diálogo com as Interpretações Realistas e Idealistas

Dissertação apresentada como requisito parcial para obtenção do título de Mestre pelo Programa de PósGraduação em Relações Internacionais da PUC-Rio.

Orientadora: Maria Regina Soares de Lima 
Geraldo Nagib Zahran Filho

\title{
A Tradição Liberal dos Estados Unidos e sua Influência nas Reflexões sobre Política Externa
} Um Diálogo com as Interpretações Realistas e Idealistas

\begin{abstract}
Dissertação apresentada como requisito parcial para obtenção do título de Mestre pelo Programa de PósGraduação em Relações Internacionais da PUC-Rio. Aprovada pela Comissão Examinadora abaixo assinada.
\end{abstract}

Maria Regina Soares de Lima

Orientadora Instituto de Relações Internacionais - PUC-Rio

Monica Herz Instituto de Relações Internacionais - PUC-Rio

Cesar Augusto Coelho Guimarães Instituto Universitário de Pesquisas do Rio de Janeiro - IUPERJ

João Franklin Abelardo Pontes Nogueira Coordenador Setorial do Centro de Ciências Sociais - PUC-Rio 
Todos os direitos reservados. É proibida a reprodução total ou parcial do trabalho sem autorização da universidade, do autor e do orientador.

\section{Geraldo Nagib Zahran Filho}

Graduou-se em Relações Internacionais pela Pontifícia Universidade Católica de São Paulo em 2002. Atualmente, é professor junto ao curso de graduação em Relações Internacionais da PUC-Rio.

Ficha Catalográfica

Zahran Filho, Geraldo Nagib

A tradição liberal dos Estados Unidos e sua influência nas reflexões sobre política externa: um diálogo com as interpretações realistas e idealistas / Geraldo Nagib Zahran Filho; orientadora: Maria Regina Soares de Lima. - Rio de Janeiro: PUC-Rio, Instituto de Relações Internacionais, 2005.

147 f. : il. ; $30 \mathrm{~cm}$.

Dissertação (mestrado) - Pontifícia Universidade Católica do Rio de Janeiro, Instituto de Relações Internacionais.

Inclui referências bibliográficas

1. Relações internacionais - Teses. 2. Política externa. 3. Estados Unidos. 4. Tradição liberal. 5. Realismo. 6. Idealismo. 7. Liberalismo. I. Lima, Maria Regina Soares de. II. Pontifícia Universidade Católica do Rio de Janeiro. Instituto de Relações Internacionais. III. Título. 


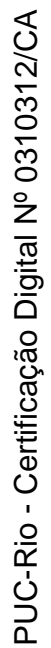

Aos meus pais, pela oportunidade e por todo seu amor 


\section{Agradecimentos}

À minha família, pela oportunidade que me deram e por todo seu apoio, mesmo quando não estavam cientes disso;

À minha orientadora, Profa. Maria Regina Soares de Lima, que encontrou tempo e paciência para guiar-me;

À Profa. Mônica Herz, pelo incentivo e ajuda, e aos demais professores do Instituto de Relações Internacionais da PUC-Rio;

A meus colegas de turma, que fizeram parte essencial dessa jornada;

A meus amigos, Leonardo Ramos, Rodrigo Cerqueira e Thiago Guimarães, sem os quais o resultado desse trabalho teria sido outro;

À Clarisse Castro, que dividiu comigo os momentos mais difíceis desse percurso;

À Luciana, Maria Helena, Regina, e todos os funcionários do IRI sempre dispostos a ajudar;

Ao CNPq e a PUC-Rio, pelo auxílio financeiro sem o qual este trabalho teria sido impossível. 


\section{Resumo}

ZAHRAN FILHO, Geraldo Nagib. A Tradição Liberal dos Estados Unidos e suas Influências nas Reflexões sobre Política Externa. Rio de Janeiro, 2005. 147p. Dissertação de Mestrado - Instituto de Relações Internacionais, Pontifícia Universidade Católica do Rio de Janeiro.

São muitas as análises sobre a política externa dos Estados Unidos, mas dentre todas elas destaca-se um tipo específico que utiliza a distinção entre políticas realistas e idealistas para caracterizá-la. A presente dissertação dialoga com esse tipo de análise da política externa do país, fornecendo uma alternativa para essa interpretação bipartida entre realismo e idealismo. Resgatando o conceito da tradição política liberal nos Estados Unidos, desenvolvido pela primeira vez pelos adeptos do paradigma da história consensual da década de 50, esta pesquisa identifica as influências dessa tradição liberal na política externa. Segundo a idéia de tradição liberal, a grande característica da política nos Estados Unidos é a ausência de uma tradição conservadora; os valores liberais estão completamente difundidos e impregnados no pensamento político do país. O maior reflexo desse fato na política externa é a capacidade dos Estados Unidos de projetarem seus interesses e valores particulares como universais. Tal característica se sobrepõe à suposta divisão da política externa em vertentes realistas e idealistas. Assim, a pesquisa se desenvolve analisando as relações existentes entre as análises de política externa que se utilizam dessa distinção entre realismo e idealismo e a tradição liberal, em dois momentos específicos: no fim da Segunda Guerra Mundial, período em que essas análises começam a se disseminar, e no pós-Guerra Fria.

\section{Palavras-chave}

Relações Internacionais; Política Externa; Estados Unidos; Tradição Liberal; Realismo; Idealismo; Liberalismo; 


\section{Abstract}

ZAHRAN FILHO, Geraldo Nagib. The Liberal Tradition of the United States and its Influences on Foreign Policy Reflections. Rio de Janeiro, 2005. 147p. MSc. Dissertation - Instituto de Relações Internacionais, Pontifícia Universidade Católica do Rio de Janeiro.

There are a great number of analyses on United States foreign policy, but among all of them there is a specific kind that uses a distinction between realist and idealist polices to classify it. The present dissertation engages itself with this specific kind of analysis, proposing an alternative to this realist-idealist interpretation. Recalling the concept of the liberal tradition of the United States, first developed by the followers of the consensus history paradigm during the decade of 50, this work identifies the influences of this liberal tradition on United States foreign policy. In accordance with the argument of the liberal tradition, the major characteristic of politics in the United States is the absence of a conservative tradition; the liberal values are completely embedded on the political thought of the country. The great reflex of this fact on foreign policy is the capacity of the United States in projecting its own interests and values as if they were universals. This characteristic supplants the supposed realist-idealist division of foreign policy. In this way, this work develops an analysis of the relations between the writings on foreign policy that use this realist-idealist division and the liberal tradition, in two specific moments: the end of World War II, at the time when this distinction starts to spread, and at the end of Cold War.

\section{Keywords}

International Relations; Foreign Policy; United States; Liberal Tradition; Realism; Idealism; Liberalism; 


\section{Sumário}

1. Introdução 11

1.1. As duas políticas externas 13

1.2. Um olhar mais abrangente sobre realismo e idealismo 15

$\begin{array}{ll}\text { 1.3. Estrutura da pesquisa } & 20\end{array}$

2 . Identificando influências: a tradição política liberal dos Estados $\begin{array}{ll}\text { Unidos e seus reflexos } & 23\end{array}$

2.1. As histórias de uma História 24

2.2. A tradição política liberal 30

2.2.1. O elemento político 31

2.2.2. O elemento religioso $\quad 35$

2.2.3. A abrangência da tradição 38

2.3. A tradição e o internacional 45

2.3.1. Uma influente despedida 45

2.3.2. Idéias de abrangência continental 51

2.4. Conclusão do capítulo 55

3 . Origens: o debate sobre relações internacionais e política externa na década de $50 \quad 57$

3.1. Antecedentes 63

3.1.1. Grandes questões da política externa 64

3.2. Apresentando o debate 69

3.2.1. A leitura majoritária da Primeira Guerra Mundial 73

3.2.2. Dialogando com a tradição liberal 81

3.2.3. O dilema de segurança e a doutrina da contenção 88

3.2.4. Outros exemplos da distinção entre realismo e idealismo 95

3.3. Conclusão do capítulo 98 
4. Realismo e idealismo nas reflexões da política externa durante a década de 90

4.1. A terceira vez

103

4.2. Reflexões sobre política externa na década de 90

4.2.1. A obra máxima de um grande expoente

4.2.2. Variações sobre um mesmo tema

4.3. Conclusão do capítulo

5 . Conclusão

132

5.1. Realismo e idealismo em perspectiva 136

5.2. Relatividade e oportunidade 139

6. Referências bibliográficas 
Eu acredito que Deus deseja que todos sejam livres. É nisso que eu acredito. E isso tem sido parte de minha política externa.

George W. Bush

Você pode chamá-los de idealistas, mas não há nada mais perigoso do que idealistas com poder $e$ guerra nas mãos e completamente errados sobre o mundo.

Seymour Hersh 